\title{
RANCANG BANGUN AKSES KUNCI PINTU GERBANG INDEKOS MENGGUNAKAN E-KTP (ELEKTRONIK KARTU TANDA PENDUDUK) BERBASIS MIKROKONTROLLER
}

\author{
Muhammad Ari Ramadhan, Sidik Noertjahjono, Febriana Santi Wahyuni \\ Program Studi Teknik Informatika S1, Fakultas Teknologi Industri \\ Institut Teknologi Nasional Malang, Jalan Raya Karanglo km 2 Malang, Indonesia \\ ari_rama01@yahoo.com
}

\begin{abstract}
ABSTRAK
Perkembangan teknologi saat ini memberikan kemudahan untuk melakukan segala sesuatu. Salah satu perkembangan teknologi terbaru adalah pada bidang komunikasi dan informasi. Salah satu teknologi terbaru dalam melakukan pertukaran data antar perangkat adalah teknologi NFC (Near Field Communication) adalah Teknologi berfungsi sebagai alat pengaman yang efektif dan efisien. Maka dalam penelitian ini dikembangkannya dengan menggunakan e-KTP sebagai gantinya dari NFC, sebagai otak dari sistem kendali ini digunakan Arduino Uno.

Beberapa hardware yang dibutuhkan dalam pembuatan sistem ini adalah Arduino Uno, MFRC-522 RFID IC Card, e-KTP, Buzzer SFM-27 DC 3-24V, Relay 5V 2 Channel, Power Supply JC-36-12 Dc 12v/12, LCD 1602A SPI WITH I2C.Setelah seluruh sensor melakukan pembacaan, mikrokontroller arduino membuat instruksi untuk selenoid doorlock yang sumber tegangannya dari power supply dan terintegrasi melalui rellay dan di support oleh responden yaitu buzzer.

Solenoid DoorLock dapat membuka dan menutup pintu gerbang ketika autentikasi yang dilakukan berhasil dan buzzer dapat menjadi alarm ketika autentikasi yang dilakukan tidak berhasil. LCD 1602A SPI I2C mampu memproses hasil masukan dari keypad, serta mampu memberikan masukan pada buzzer sehingga buzzer dapat berfungsi sebagai indikator peringatan dalam bentuk bunyi. Rellay mampu bekerja dengan baik untuk mengaktifkan pergerakan dari Solenoid DoorLock untuk membuka dan mengunci pintu. Sistem dapat membuka dan menutup pintu gerbang sesuai dengan rancangan yang telah direncanakan, yaitu dengan autentikasi RFID RC522 pada Arduino Uno.
\end{abstract}

Kata kunci : E-KTP, Keamanan, Mikrokontroller

\section{PENDAHULUAN}

Perkembangan teknologi saat ini memberikan kemudahan untuk melakukan segala sesuatu. Salah satu perkembangan teknologi terbaru adalah pada bidang komunikasi dan informasi. Perkembangan teknologi pada perangkat keras seperti telepon genggam, membuat perangkat lunak yang digunakan pun ikut berkembang. Untuk melakukan pertukaran data antar perangkat sudah banyak digunakan seperti Bluetooth, WiFi dan beragam komunikasi nirkabel lainnya. Salah satu teknologi terbaru dalam melakukan pertukaran data antar perangkat adalah teknologi NFC (Near Field Communication) adalah Teknologi berfungsi sebagai alat pengaman yang efektif dan efisien.

Teknologi NFC (Near Field Communication) merupakan pengembangan dari teknologi RFID (Radio Frequency Identification) yang sudah ada sebelumnya. NFC tidak memerlukan pengaturan manual koneksi karena secara otomatis bias menghubungkan kedua perangkat dengan cepat. NFC (Near Field Communication) memiliki tingkat keamanan yang tinggi dan aman untuk digunakan.

Saat ini membutuhkan sistem keamanan yang tinggi yang dapat diterapkan pada indekos dengan akses terbatas. Indekos tersebut hanya bisa diakses oleh penghuni indekosnya sendiri dan pemiliknya demi keamanan kendaraan dan dalam ruangan seperti ruang kamar. Untuk itu, digunakan NFC (Near Field Communication) sebagai pembuka kunci pintu gerbang indekos untuk mengendalikan akses sebuah indekos. Namun dalam penelitian ini dikembangkannya dengan menggunakan E-KTP sebagai gantinya dari NFC, sebagai otak dari sistem kendali ini digunakan Arduino Uno.

\subsection{Rumusan Masalah}

Setelah dipaparkan pada latar belakang, maka dapat disimpulkan dengan masalah sebagai berikut :

a. Bagaimana merancang dan membangun sistem keamanan pintu gerbang indekos menggunakan E-KTP?

b. Bagaimana mengembangkan sistem keamanan indekos menggunakan mikrokontroller?

c. Bagaimana melakukan pengujian pada sistem keamanan pintu gerbang indekos menggunakan E-KTP?

\subsection{Batasan Masalah}

Agar dalam penulisan penelitian yang dibuat tidak meluas, maka penelitian ini memiliki batasan masalah sebagai berikut:

a. Datasheet yang digunakan pada pengembangan aplikasi adalah hasil pengambilan data langsung dari Modul RFID MFRC - 522 13.56Mhz. 
b. Teknologi E-KTP yang digunakan harus memiliki Unique Identifier (UID)/Identitas perangkat yang telah terintregrasi pada modul RFID MFRC - 522 13.56Mhz melalui keypad $4 \times 4$ matrix.

c. Hak akses hanya dapat digunakan oleh pengguna pada penghuni Indekos yang memiliki E-KTP yang telah terintegrasi dengan modul RFID MFRC - 522 13.56Mhz.

d. Pada alat sistem kendali ini, sumber tegangan menggunakan USB interface atau Adaptor 12V pada mikropengendali Arduino Uno.

e. Alat yang berfungsi sebagai door lock pada pintu adalah Solenoid Push and Pull dan Magnetic lock serta menggunakan sumber tegangan Power Suplly 12V 3 A.

f. Keypad 4x4 matrix digunakan untuk menginput maupun mendelete UID E-KTP pada modul RFID MFRC - 522 13.56Mhz.

g. Bahasa pemrograman yang digunakan yaitu $\mathrm{C}$ Arduino untuk Arduino.

\subsection{Tujuan}

Adapun tujuan yang diharapkan dari pelaksanaan penelitian ini sebagai berikut :

a. Untuk merancang dan membangun sistem keamanan pada pintu gerbang indekos menggunakan Modul RFID MFRC - 522 13.56Mhz.

b. Menguji E-KTP sebagai pembuka kunci pintu gerbang indekos.

c. Mempelajari konsep atau cara kerja teknologi EKTP dari Mikrokontroler.

\section{TINJAUAN PUSTAKA}

\subsection{Penelitian Terdahulu}

Berdasarkan penelitian yang dilakukan oleh Sarono Widodo, Ghassan Z.Sasmita, Lutfia N.Sari dan Abu Hasan pada tahun 2018, peneliti memaparkan bahwa perlunya keamanan pintu menggunakan perangkat keras yang berbasis mikrokontroller. Pada penelitian tersebut menunjukkan keuntungan dari "Sistem Akses Pintu Menggunakan e-KTP Sebagai Kunci Elektronik Berbasis Near Field Communication Dimonitor Melalui Jaringan Komputer", pada penelitian tersebut juga disebutkan bahwa apa saja sensor-sensor yang digunakan antara lain yaitu sensor RFID, dan sensor selenoid doorlock untuk menggerakkan pintu.[1]

Kemudian pada tahun 2016, Eko Saputro dan Hari Wibawanto melakukan penelitian tentang "Rancang Bangun Pengaman Pintu Otomatis Menggunakan E-KTP Berbasis Mikrokontroler Atmega328". Didapati pada penelitian tersebut bertujuan membuat suatu alat pengaman pintu yang mudah, murah, praktis dalam penggunaan untuk dapat meningkatkan kenyamanan dan keamanan dalam membuka pintu tanpa harus memegang bermacam-macam kunci yang mungkin sangat mengganggu. Alat ini akan mendeteksi/bekerja setelah sensor RFID mendeteksi E-KTP yang dihadapkan, yang secara otomatis akan membaca EKTP untuk membuka pengunci pada pintu yang berupa solenoid.[2]

Pada tahun 2018, Azhar Kurniana melakukan penelitian yang berjudul "Perancangan Dan Implementasi Prototipe Sistem Kunci Pintu Menggunakan E-Ktp Berbasis Android". Pada penelitian tersebut yaitu tujuannya adalah pada umumnya suatu rumah memiliki beberapa pintu yang terpasang di rumahnya, dengan adanya lebih dari satu pintu yang tepasang di suatu rumah maka anak kunci yang harus di miliki ialah sejumlah banyaknya pintu yang terpasang di rumah tersebut, dengan banyaknya anak kunci yang dimiliki akan mempersulit manusia untuk membuka pintu terlebih jika manusia sedang dalam keaadan tergesa - gesa. Ada beberapa komponen maupun sensor yang digunakan pada penelitian ini yaitu Smartphone Android, HC-05, Toogle Switch dan Selenoid DoorLock.[3]

Dan pada tahun 2014, Tadu Puasandi melakukan penelitian tentang "Sistem Akses Kontrol Kunci Elektrik Menggunakan Pembacaan E-Ktp". Pada penelitian tersebut bertujuan untuk menghindari kunci duplikat yang akan mengakibatkan tindak kejahatan pada rumah ataupun ruangan perkantoran adapun sensor yang digunakan yaitu Modul NFC, Xbee, modul RTC 1307 dan sensor Hall Effect A3144.[4]

Dan tahun Desember 2019, Wisnu Wendanto, D Jayus Nor Salim dan Wahyu Trisna Putra melakukan penelitian yang berjudul "Rancang Bangun Sistem Keamanan Smart Door Lock Menggunakan E-KTP (Elektronik Kartu Tanda Penduduk) Dan Personal Identification Number Berbasis Arduino Mega R3". Pada penelitian ini untuk mencegah pembobolan pintu rumah dan pencurian yang terjadi di Perumahan Margo Asri Sragen ketika ditinggal pemilik rumah. Sistem keamanan alat ini terdiri beberapa komponen utama yaitu e-KTP, RFID reader, mikrokontroler, PIN dan solenoid door lock.[5]

\subsection{Dasar Teori}

\subsubsection{Arduino Uno}

Arduino Uno adalah board mikrokontroler berbasis ATmega328 (datasheet). Memiliki 14 pin input dari output digital dimana 6 pin input tersebut dapat digunakan sebagai output PWM dan 6 pin input analog, $16 \mathrm{MHz}$ osilator kristal, koneksi USB, jack power, ICSP header, dan tombol reset. Untuk mendukung mikrokontroler agar dapat digunakan, cukup hanya menghubungkan Board Arduino Uno ke komputer dengan menggunakan kabel USB atau listrik dengan AC yang-ke adaptor-DC atau baterai untuk menjalankannya. 


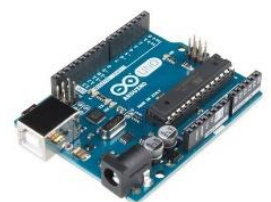

Gambar 1 Arduino Uno

\subsubsection{RFID MFRC522}

RFID-MFRC522 (Radio Frequency Identification) merupakan suatu teknologi yang memanfaatkan frekuensi radio sebagai pengidentifikasian terhadap suatu objek.

RFID mempunyai 2 bagian komponen utama yang tak dapat dipisahkan, yaitu :

a. RFIDTag

Merupakan sebuah perangkat yang akan diidentifikasi oleh RFID reader yang dapat berupa perangkat pasif maupun aktif yang berisi suatu data atau informasi.

b. RFID Reader

Berfungsi untuk membaca data dari RFID Tag. RFID Reader dibedakan menjadi 2 macam, antara lain :

- Pasif : hanya bisa membaca data dari RFID tag aktif.

- Aktif : dapat membaca data RFID tag pasif

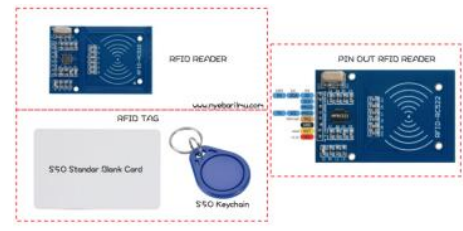

Gambar 2 RFID MFRC522

\subsubsection{DoorLock}

Solenoid ini berfungsi sebagai aktuator. Prinsip dari solenoid sendiri akan bekerja sebagai pengunci dan akan aktif ketika diberikan tegangan. Didalam solenoid terdapat kawat yang melingkar pada inti besi. Ketika arus listrik mengalir melalui kawat ini, maka terjadi medan magnet untuk menghasilkan energi yang akan menarik inti besi ke dalam.

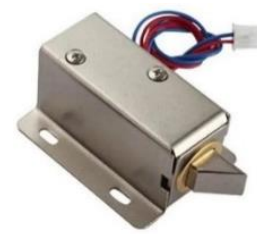

Gambar 3 Selenoid DoorLock

\subsubsection{Buzzer}

Buzzer adalah sebuah komponen elektronika yang berfungsi untuk mengubah getaran listrik menjadi getaran suara getaran listrik menjadi getaran suara. Pada dasarnya prinsip kerja buzzer hampir sama dengan loudspeaker, jadi buzzer juga terdiri dari kumparan yang terpasang pada diafragma dan kemudian kumparan tersebut dialiri arus sehingga menjadi elektromagnet. Buzzer biasa digunakan sebagai indikator bahwa proses telah selesai atau terjadi suatu kesalahan pada sebuah alat (alarm).

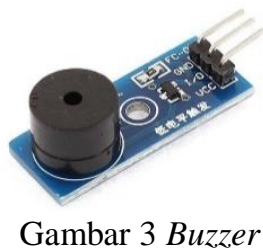

\subsubsection{Module Relay 2 Channel 5V}

Relay adalah suatu peranti yang bekerja berdasarkan elektromagnetik untuk menggerakan sejumlah kontaktor yang tersusun atau sebuah saklar elektronis yang dapat dikendalikan dari rangkaian elektronik lainnya dengan memanfaatkan tenaga listrik sebagai sumber energinya. Kontaktor akan tertutup (menyala) atau terbuka (mati) karena efek induksi magnet yang dihasilkan kumparan (induktor) ketika dialiri arus listrik. Berbeda dengan saklar, pergerakan kontaktor (on atau off) dilakukan manual tanpa perlu arus listrik. Relay yang paling sederhana ialah relay elektromekanis yang memberikan pergerakan mekanis saat mendapatkan energi listrik. Secara sederhana relay elektromekanis ini didefinisikan sebagai Saklar yang digerakkan secara mekanis oleh daya atau energi listrik.

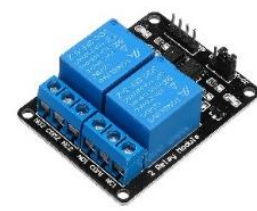

Gambar 4 Relay

\subsubsection{Switch Mode Power Supply 12V 3A}

Switch-Mode Power Supply (SMPS) adalah jenis Power Supply yang langsung menyearahkan (rectify) dan menyaring (filter) tegangan Input AC untuk mendapatkan tegangan DC. Tegangan DC tersebut kemudian di-switch $O N$ dan $O F F$ pada frekuensi tinggi dengan sirkuit frekuensi tinggi sehingga menghasilkan arus AC yang dapat melewati Transformator Frekuensi Tinggi.

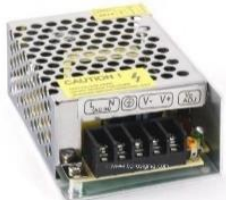

Gambar 5 Switch-Mode Power Supply 12V 3A

\subsubsection{E-KTP}

KTP berbasis Nomor Induk Kependudukan atau disebut sebagai e-KTP menggunakan smart card. eKTP mengacu pada standar ISO $14443 \mathrm{~A} / \mathrm{B}$ bekerja dengan baik pada kisaran suhu antara -25 oC sampai 
dengan 70 oC dan dengan kisaran frekuensi operasional $13,56 \mathrm{MHz} \pm 7 \mathrm{KHz}[3]$. e-KTP mempunyai SAM (secure access module) berupa 4 bytes UIDs (Unique identifier) dalam range kombinasi 10 digit.

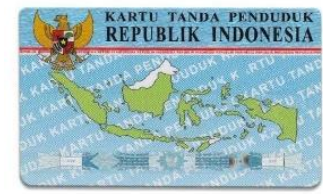

Gambar 6 E-KTP

\subsubsection{LCD 1602A SPI WITH I2C}

Merupakan LCD 16x2 yang dilengkapi modul I2C untuk meringkas pengkabelan dan menghemat penggunaan pin pada mikrokontroler nantinya. Dengan adanya modul I2C Anda hanya membutuhkan 4 buah pin pada mikrokontroler untuk mengakses LCD (VCC, GND, SCL, SDA). Bandingkan dengan LCD paralel biasa yang harus menggunakan 8 pin mikrokontroler untuk dapat mengakses LCD.

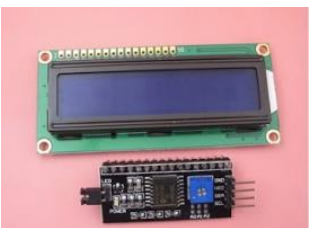

Gambar 7 LCD 1602A SPI WITH I2C

\section{METODE PENELITIAN}

\subsection{Analisis Kebutuhan}

Kebutuhan dalam sistem keamanan pada kelistrikan motor ini mencakup dua hal yaitu kebutuhan fungsional dan kebutuhan non fungsional. Berikut ini adalah penjabaran kebutuhan-kebutuhan tersebut.

\section{Kebutuhan Fungsional}

Pada sistem keamanan pada kelistrikan motor ini memiliki kebutuhan Fungsional yaitu:

1. Sistem mampu mengirim notifikasi dan menampilkan lokasinya

2. Sistem mampu mengontrol kelistrikan pada sepeda motor

\section{Kebutuhan Non Fungsional}

Pada sistem keamanan pada kelistrikan motor ini memiliki kebutuhan Fungsional yaitu:

1. Alat ini dibuat seminimalis mungkin sehingga memudahkan dalam proses penggunaan dan pemasangannya.

2. Sistem akan lebih optimal bila diterapkan di luar ruangan

\subsection{Deskripsi Sistem dan Diagram Blok}

Sistem Akses Kunci Pintu Gerbang Indekos Berbasis Mikrokontroller merupakan suatu trobosan atau penelitian yang dapat menekan angka untuk tindak kriminal dengan kekerasan maupun tanpa kekerasan. Beberapa hardware yang dibutuhkan dalam pembuatan sistem ini adalah Arduino Uno, MFRC-522 RFID IC Card, E-KTP, Buzzer SFM-27 DC 3-24V, Relay 5V 2 Channel, Power Supply JC36-12 Dc 12v/12, LCD 1602A SPI WITH I2C.

Setelah seluruh sensor melakukan pembacaan, mikrokontroller arduino membuat instruksi untuk selenoid doorlock yang sumber tegangannya dari power supply dan terintegrasi melalui rellay dan di support oleh responden yaitu buzzer. Berikut penjelasan mengenai perancangan hardware dari sistem.

Kebutuhan perangkat tersebut sesuai dengan blok diagram alat yang dibuat. Gambar blok diagram ditunjukkan pada Gambar berikut.

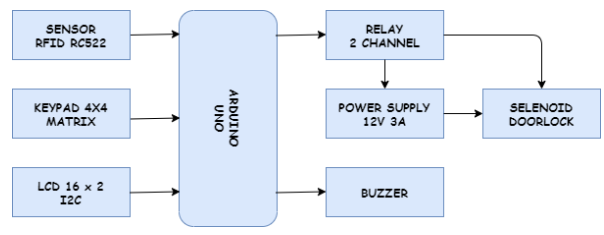

Gambar 8 Diagram Blok Sistem Akses Kunci Pintu Gerbang Indekos Berbasis Mikrokontroller

\subsection{Flowchart Sistem}

FlowChart program sistem pada sistem Akses Kunci Pintu Gerbang Indekos Berbasis Mikrokontroller berikut menggambarkan alur kerja sistem yang akan berjalan dimulai dari pembacaan eKTP sampai dimana selenoid doorlock terbuka. Berikut alur program pada sistem :

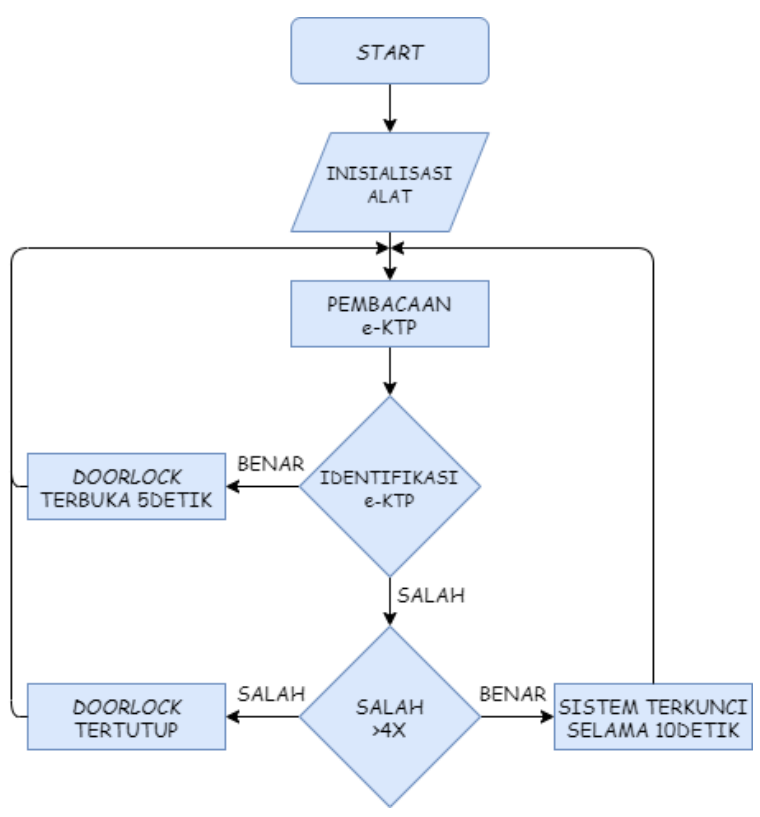

Gambar 9 Flowchart Sistem

Pada flowchart diatas merupakan penjelasan dari keseluruhan alur sistem. Dimulai dari inisialisai alat RFID 522, kemudian hasil baca sensor RFID digunakan untuk acuan pembukaan selenoid doorlock 
yang satuan daya menggunakan power supply $12 \mathrm{~V}$ 3A dan terintegrasi dengan buzzer sebagai pertanda bekerjanya maupun tidak bekerjanya alat tersebut.

\subsection{Skema Rangkaian Alat}

Alokasi pin adalah penempatan pin-pin yang terhubung satu sama lain pada minimum sistem Arduino Uno, adapun alokasi pin pada hardware yang dibutuhkan dapat dilihat pada gambar berikut.

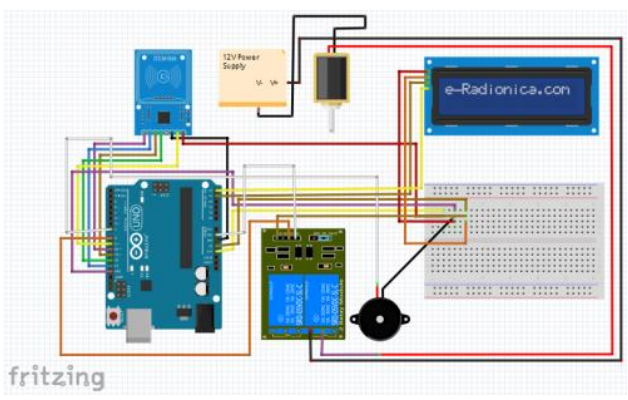

\section{HASIL DAN PENGUJIAN}

\subsection{Pengujian Model Design}

Pengujian ini merupakan pengujian hardware pada alat yang sudah di kerjakan, lalu dilakukan pada setiap komponen yang terhubung pada setiap minimum sistem arduino.

\subsection{Hasil Implementasi Software}

Pada Serial Monitor ini bagian dari pengecekkan bahwa ID pada card atau key NFC, E-KTP sudah terdaftar pada sketch dan selenoid doorlock akan aktif jika output true.

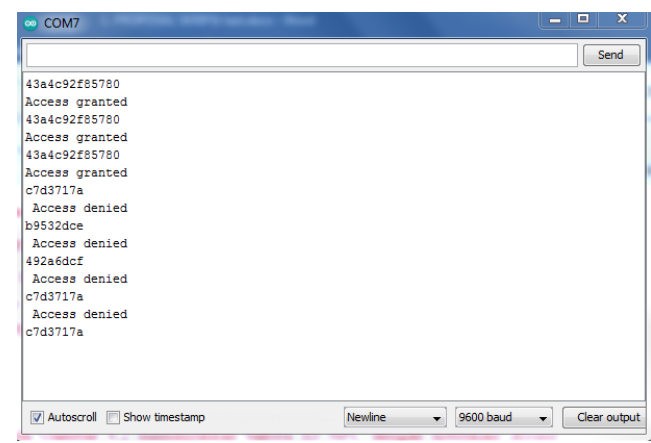

Gambar 11 Notifikasi ID NFC True or False pada Serial Monitor

Pada Gambar 11 menunjukkan bahwa ID NFC dengan notifikasi Access Granted adalah ID yang output true dan pasti selenoid doorlock aktif atau terbuka selama 5detik, sedangkan ID NFC dengan notifikasi Access Denied adalah ID yang output false dan selenoid doorlock tidak aktif atau terkunci serta buzzer bunyi selama 3 detik dikarenakan ID tersebut belum terdaftar pada RFID Reader.

\subsection{Hasil Implementasi Hardware}

Pada implementasi perangkat keras sistem Akses Kunci Pintu Gerbang Indekos Berbasis Mikrokontroller ini yang dibuat berbentuk rangkaian RFID Reader pada arduino dimana untuk pengaktifan selenoid doorlock atau pembuka tuas kunci sebagai langkah terakhir. Bentuk rangkaian alat terlihat seperti pada Gambar 12.

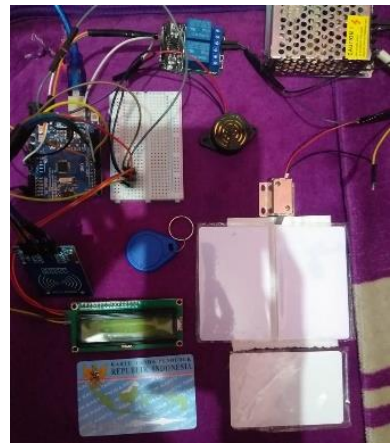

Gambar 12 Implementasi Komponen RFID Reader RC522 dengan Selenoid DoorLock

Model desain sistem RFID Reader yang dibuat sesuai dengan perancangan hardware. Pada Gambar 4.2 menunjukkan model desain hardware yang terdiri dari beberapa komponen dengan fungi dan tugas masing-masing. Pengujian ini dilakukan untuk mengetahui pembacaan sensor RFID Reader , Selenoid DoorLock sebagai langkah akhir.

\subsection{Tampilan Awal}

Pada LCD 16x2 I2C ini menampilkan tampilan awal yang menyatakan alat siap untuk penginisialisasian E-KTP sebagai akses KEAMANAN KOS.

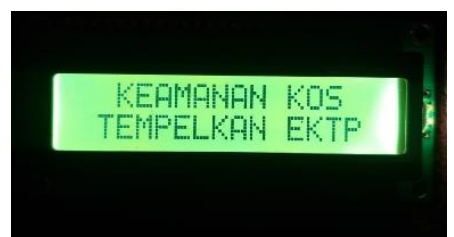

Gambar 13 Tampilan awal sebagai identifikasi atau notifikasi

Pada Gambar 13 menampilkan pada LCD 16x2 I2C yaitu ada notifikasi bahwa alat tersebut yaitu KEMANAN KOS dan segera untuk TEMPELKAN E-KTP.

\subsection{Tampilan Hasil Benar}

Pada LCD 16x2 I2C ini menampilkan tampilan SILAKAN MASUK dengan UID yang menyatakan selenoid terbuka pada KEAMANAN KOS.

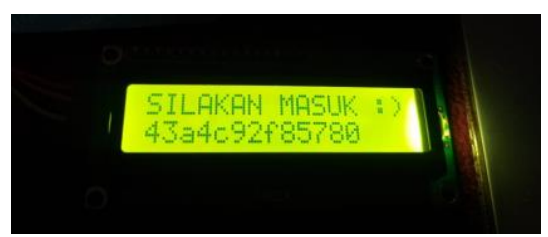

Gambar 14 Tampilan Hasil Benar 
Pada Gambar 14 menampilkan pada LCD 16x2 I2C yaitu ada notifikasi bahwa penginisialisasian benar dan ada perintah SILAKAN MASUK disertai dengan UID EKTP.

\subsection{Tampilan Hasil Salah}

Pada LCD 16x2 I2C ini menampilkan tampilan AKSES DITOLAK dengan UID yang menyatakan selenoid tertutup pada KEAMANAN KOS dan apabila pengaksesan lebih dari 4x dengan K-KTP yang salah RFID akan berhenti dan tidak bisa membaca NFC ataupun EKTP selama waktu yang di tentukan dan tertera pada Gambar 16.

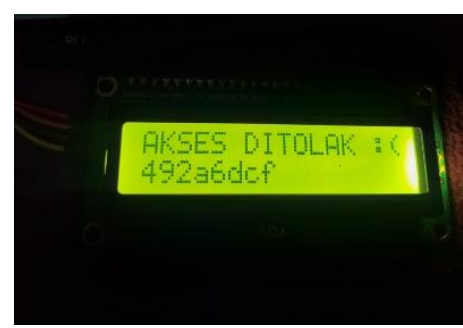

Gambar 15 Tampilan Hasil Salah

Pada Gambar 15 menampilakn pada LCD 16x2 I2C yaitu ada notifikasi bahwa penginisialisasian salah dan perintah AKSES DITOLAK disertai dengan UID E-KTP.

\subsection{Tampilan Alat Berhenti Sementara Waktu}

Pada LCD 16x2 I2C ini menampilkan tampilan Sistem Terkunci selama 10 detik dan Mohon Tunggu, Sistem ini akan Terkunci jika kita menempelkan NFC atau E-KTP yang salah atau belum terintregasi dengan RFID RC522 lebih dari $4 x$.

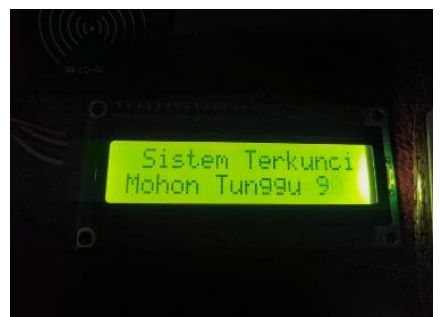

Gambar 16 Sistem Terkunci atau berhenti (Halt)

Pada Gambar 16 menampilkan pada LCD 16x2 I2C bahwa Sistem Terkunci Mohon Tunggu selama 10detik dikarenakan penempelan NFC atau E_KTP yang salah lebih dari $4 \mathrm{x}$ dan akan normal atau bisa digunakan setelahnya.

\subsection{Penambahan UID}

Pada Mode ini untuk UID pada card atau key NFC , E-KTP yang belum terdaftar atau terintregasi dengan RFID RC522 bisa ditambahkan menggunakan keypad 4x4 matrix yang termonitoring dengan LCD 16x2 I2C, berikut step by step untuk penambahan UID pada RFID RC522.

1. Tekan Tombol A pada keypad $4 \mathrm{x} 4$ matrix.

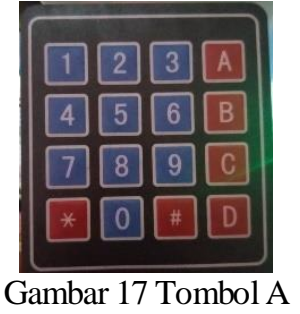

Penambahan UID pada RFID RC522 yaitu menggunakan keypad 4x4 matrix dengan monitoring LCD $16 \times 2$ I2C dan harus menekan tombol A sebagai langkah awal.

1. Tampilan pada LCD $16 \times 2$ I2C

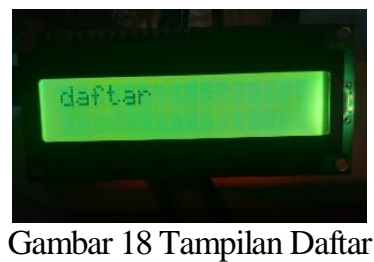

Pada Gambar 4.8 LCD 16x2 I2C menampilkan notifikasi (daftar) yaitu bahwa RFID RC522 bisa menambahkan UID yang akan disimpan pada Arduino Uno pada library EEPROM tanpa memerlukan penambahan micro sd sebagai tempat penyimpanan UID.

2. Tampilan pada LCD 16x2 I2C

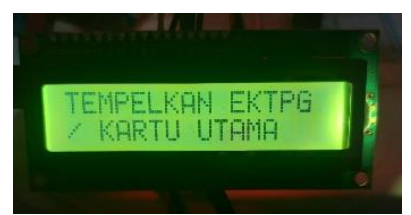

Gambar 19 Tampilan TEMPELKAN EKTP/KARTU UTAMA

Pada Gambar 19 LCD 16x2 I2C menampilkan notifikasi (TEMPELKAN EKTP/KARTU UTAMA) yaitu perintah atau syarat jika ingin menambahkan UID baru pada RFID RC522.

\subsection{Penghapusan UID}

Pada Mode ini untuk UID pada card atau key NFC , E-KTP yang sudah terdaftar atau terintregasi dengan RFID RC522 bisa dihapus menggunakan keypad $4 \times 4$ matrix yang termonitoring dengan LCD $16 \times 2 \mathrm{I} 2 \mathrm{C}$, berikut step by step untuk penghapusan UID pada RFID RC522.

1. Tekan Tombol B pada keypad $4 \times 4$ matrix

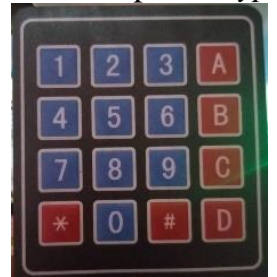

Gambar 20 Tombol B 
Penghapusan UID pada RFID RC522 yaitu menggunakan keypad 4x4 matrix dengan monitoring LCD 16x2 I2C dan harus menekan tombol B sebagai langkah awal.

\section{Tampilan pada LCD 16x2 I2C}

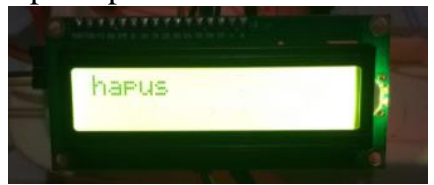

Gambar 21 Tampilan Hapus

Pada Gambar 21 LCD 16x2 I2C menampilkan notifikasi (hapus) yaitu bahwa RFID RC522 bisa menghapus UID yang akan dihapus pada Arduino Uno pada library EEPROM tanpa memerlukan penambahan micro $s d$ sebagai tempat penyimpanan UID.

Tampilan pada LCD 16x2 I2C

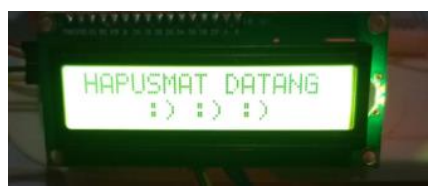

Gambar 22 UID card atau key NFC, E-KTP tehapus

Pada Gambar 22 LCD 16x2 I2C menampilkan notifikasi (HAPUS) setelah menempelkan card atau key NFC , E-KTP yang akan kita hapus pada RFID RC522.

\subsection{Keamanan}

Pada Mode ini adalah untuk keamanan yaitu untuk memberikan akses pada indekost siapa saja yang boleh masuk, berikut step by step untuk keamanan.

1. Tekan Tombol C pada keypad 4x4 matrix

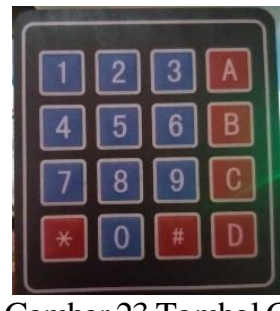

Mode keamanan pada RFID RC522 yaitu menggunakan keypad 4x4 matrix dengan monitoring LCD 16x2 I2C dan harus menekan tombol $\mathrm{C}$ sebagai langkah awal.

\section{Tampilan pada LCD $16 \times 2$ I2C}

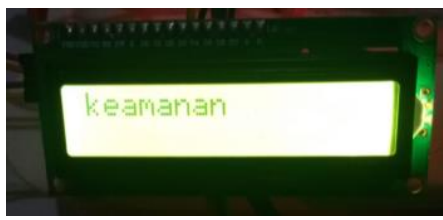

Gambar 24 Tampilan Keamanan
Pada Gambar 24 LCD 16x2 I2C menampilkan notifikasi (keamanan) yaitu bahwa RFID RC522 siap untuk menginisialisasi card atau key NFC , E-KTP mana yang sudah terintegrasi agar selenoid doorlock terbuka seperti pada Gambar 14.

\section{KESIMPULAN DAN SARAN \\ 5.1 Kesimpulan \\ Berdasarkan beberapa pengujian yang telah dilakukan, menghasilkan beberapa kesimpulan} diantaranya :

1. Solenoid DoorLock dapat membuka dan menutup pintu gerbang ketika autentikasi yang dilakukan berhasil dan buzzer dapat menjadi alarm ketika autentikasi yang dilakukan tidak berhasil.

2. LCD 1602A SPI I2C mampu memproses hasil masukan dari keypad, serta mampu memberikan masukan pada buzzer sehingga buzzer dapat berfungsi sebagai indikator peringatan dalam bentuk bunyi.

3. Rellay mampu bekerja dengan baik untuk mengaktifkan pergerakan dari Solenoid DoorLock untuk membuka dan mengunci pintu.

4. Sistem dapat membuka dan menutup pintu gerbang sesuai dengan rancangan yang telah direncanakan, yaitu dengan autentikasi RFID RC522 pada Arduino Uno.

\subsection{Saran}

Adapun beberapa saran yang dapat diberikan setelah melakukan pengembangan sistem dan beberapa pengujian, diantaranya :

1. Untuk penelitian selanjutnya agar dapat menambahkan alternatif untuk membuka pintu gerbang dari dalam.

2. Perlunya baterai sebagai cadangan power supply dan dapat berpindah otomatis jika sumber tegangan pada PLN padam.

3. Untuk penelitian selanjutnya agar dapat menambahkan mekanisme management password.

4. Untuk penelitian selanjutnya agar dapat menambahkan notifikasi lain yang berupa suara dari komponen DFD Player.

\section{DAFTAR PUSTAKA}

[1] Azhar Kurniana, M. A. (2018). PERANCANGAN DAN IMPLEMENTASI PROTOTIPE SISTEM KUNCI PINTU MENGGUNAKAN E-KTP BERBASIS ANDROID. e-Proceeding of Engineering : Vol.5, No.1, 55.

[2] Eko Saputro, H. W. (2016). Rancang Bangun Pengaman Pintu Otomatis Menggunakan E-KTP Berbasis Mikrokontroler Atmega328. Jurnal Teknik Elektro Vol. 8 No. 1, 1411 - 0059.

[3] Sarono Widodo, G. Z. (2016). Sistem Akses Pintu Menggunakan e-KTP Sebagai Kunci Elektronik Berbasis Near Field Communication Dimonitor Melalui Jaringan Komputer. Prosiding Seminar Nasional FDI, 2460-5271. 
[4] Tadu Puasandi, M. R. (2014). SISTEM AKSES KONTROL KUNCI

ELEKTRIK MENGGUNAKAN PEMBACAAN E-KTP. Jurnal Tadu Puasandi.
[5] Tadu Puasandi, M. R. (2014). SISTEM AKSES KONTROL KUNCI ELEKTRIK MENGGUNAKAN PEMBACAAN E-KTP. Jurnal Tadu Puasandi. 